\title{
Examining Relationships between Academic and Social Achievement Goals and Routes to Happiness
}

\author{
Christopher O. Walker, ${ }^{1}$ Tina D. Winn, ${ }^{2}$ and Rachel M. Lutjens ${ }^{1}$ \\ ${ }^{1}$ Department of Psychology, University of Science and Arts of Oklahoma, 1727 W. Alabama Chickasha, OK 73717, USA \\ ${ }^{2}$ Department of Psychology and Family Studies, Oklahoma Christian University, P.O. Box 11000, Oklahoma City, OK 73136, USA
}

Correspondence should be addressed to Christopher O. Walker, cwalker@usao.edu

Received 27 March 2012; Revised 9 July 2012; Accepted 18 July 2012

Academic Editor: Eddie Denessen

Copyright (C) 2012 Christopher O. Walker et al. This is an open access article distributed under the Creative Commons Attribution License, which permits unrestricted use, distribution, and reproduction in any medium, provided the original work is properly cited.

\begin{abstract}
The purpose of the current study was to examine the relationships among social and academic achievement goals and the route to happiness selected by a sample of college students. According to Waterman (1993) there are two distinct routes to happiness: eudaimonia and hedonic enjoyment. Hedonic enjoyment has been defined as the pursuit of proximal goals and immediate pleasure, while eudaimonia is best defined as the long-term commitment to pursue "self-realization" (Waterman, 1993). A sample of 132 college students completed a research packet containing an informed consent, demographics form, and three questionnaires. The results suggested that one's route to happiness was related to the academic and social achievement goal orientation of the participants. A call is made for additional research to examine the interrelations among variables traditionally considered in cognitive-motivational research and variables considered to be a part of the positive psychology movement (e.g., happiness).
\end{abstract}

\section{Introduction}

Attempts to understand and achieve a state of happiness are not new. Over two-thousand years ago Aristotle theorized that happiness is the primary pursuit of mankind and that all other forms of attainment (i.e., an increase in personal health and wealth) are subordinate in the service of maintaining or increasing one's current state of happiness. More recently, Csikszentmihalyi [1] described happiness as an essential element in experiencing "flow" which he defined as a state of "optimal experience" derived from experiencing and exhibiting "mastery" over a challenging yet meaningful and personally relevant task (p. 3-4). Csikszentmihalyi [1] further argued that a state of happiness "is a condition that must be prepared for, cultivated, and defended" and will arise as one "learn [s] to control inner experience" through the meaningful and reflective interpretation of external realities (pg. 2). This line of argument clearly suggests that as a state of happiness can be gained it can also be lost if left "undefended." Similarly, $[2,3]$ concluded that happiness has an essential cognitive foundation and stated "happiness cannot be pursued; it must ensue. a human being is not one in pursuit of happiness but rather in search of a reason to become happy" (pg. 162). Further, Seligman [4] has argued that happiness is one of five key contributors to well-being along with engagement (analogous to Csikszentmihalyi's concept of flow), meaning, accomplishment, and positive interpersonal relations and that factors such as hope [5] and optimism (i.e., one's ability and willingness to adopt an optimistic appraisal of a given situation) directly contribute to and support one's current state of happiness.

Ultimately, we argue that happiness is a malleable psychological construct that directly contributes to an individual's broader estimate of their own well-being. We further argue that happiness is dependent upon one's cognitive state and therefore can be positively altered depending upon one's ability and/or willingness to adopt a more optimistic explanatory style when confronted by conditions within a variety of external contexts $[4,6,7]$. Regarding malleability, researchers have noted successful interventions within a 
variety of contexts including but not limited to education [8], mental health [9], and increasing psychological resilience in the USA Army [10].

Additional research within the educational and positive psychology subfields has consistently indicated that one's level and/or type of happiness and the nature of one's pursuit of goals are linked, both directly and indirectly, to academically and socially related outcomes [11-15]. Regarding goals, research has consistently indicated that the nature of the goals we set in either academic or social contexts has the capacity to predict and explain a host of attitudes and behaviors that will likely impact our lives in some concrete and tangible way [16-18]. For example, recent findings suggest that one's adopted goal orientation, or the goal orientation of one's teacher, can have a direct relationship with the development of one's numeracy skills $[18,19]$, one's readiness to seek out social comparison information [20], and "achievement emotions" including but not limited to enjoyment, boredom, anger, hope, pride, and shame [21].

The bulk of previous research examining the intersection of cognitive-motivational factors and happiness has considered happiness an outcome of one's cognitive-motivational orientation. However, recent studies have begun to address the possibility that happiness can serve as an important predictor when trying to explain academic motivation, behaviors, and outcomes. More specifically, Lyubomirsky et al. [14] have stated that "happy people appear to be more successful than their less happy peers in the three primary life domains: work, relationships, and health" (p. 825). The intent of the current study, in part, is to examine happiness in a manner consistent with Lyubomirsky et al. [14] while widening the scope of investigation to include a wider range of potential cognitive-motivational variables namely, academic and social achievement goals.

For the current paper, happiness will be examined within two of Lyubomirsky et al.'s [14] three aforementioned domains of life, namely, work (as it relates to academics) and social relationships. As few, if any, areas stand to have such a potent impact on the formation of an adolescent's sense of self and, thereby, the psychological foundation of adulthood, it would seem beneficial to examine the interrelations among factors which could assist in explaining the nature of attitudes and behaviors within those aforementioned domains. The following sections will describe each set of variables used in the present study and present relevant findings from past research.

\section{Routes of Happiness}

Instead of viewing happiness as a unitary construct and, as a consequence, simply examining the level of happiness one may have, scholars have typically differentiated between two distinct forms of happiness and labeled them hedonia and eudaimonia, respectively [15]. Both types of happiness have consistently been found to impact the selection of activities and one's willingness to be resilient within those activities $[15,22]$. For example, someone may play the piano because it is fun and feels good in the moment (hedonic enjoyment) or as a means of developing their musical talent and pursuing their musical and/or creative potential (eudaimonic happiness). The key reason for making such a distinction is that depending on the underlying orientation which guides the choice to play piano, an individual will likely differ with respect to the quality and quantity of time, effort, and energy dedicated to that specific task [22].

Waterman [15] has stated that, "hedonic enjoyment may be expected to be felt whenever pleasant affect accompanies the satisfaction of needs, whether physically, intellectually, or socially based" (p. 679). However, a potentially limiting facet of hedonic enjoyment is that it is thought to be exclusively based on the successful resolution of a concrete and specific event, bound by time and place and therefore exemplified by an emotional surge which is likely to be short lived. Conversely, eudaimonia is exemplified in the pursuit of longterm well-being and fulfillment, similar to Maslow's [23] notion of self-actualization, as the route to happiness. As such, Waterman [15] indicated that eudaimonia arises from "efforts to live in accordance with the [true self], to realize those potentials" (p. 678).

While eudaimonia and hedonic enjoyment may, in some cases, be positively related, they are thought to represent distinct constructs. For example, Waterman [15] has argued that pursuing eudaimonia is a sufficient but not necessary condition for experiencing hedonic pleasure; however, the reverse of that relationship does not seem to hold true due to the fact that experiencing hedonic pleasure is often temporary and not sufficient to bring about a sense of longterm fulfillment. Further, Ryan et al. [22] proposed an empirical model that presupposes "goals, regulatory styles, and capacities for mindfulness" as fundamental aspects of eudaimonic living (p. 163) and that the pursuit of eudaimonic pleasure brings about a more complete and more stable sense of well-being than does pursuit of hedonic enjoyment. However, it should be noted that research findings do not imply that the pursuit of hedonic enjoyment is a categorically maladaptive orientation. Rather one should understand that it is perhaps the lone pursuit of hedonic enjoyment, either at the expense of others or in the absence of a pursuit of longterm fulfillment, which can render hedonic enjoyment less adaptive when compared to eudaimonic happiness.

\section{Academic Achievement Goals}

The type(s) of achievement goals one pursues has been found to result in differing patterns of academic and social performance $[12,16,17]$. In recent years, academic achievement goals have consistently been divided into three distinct categories each having a differential impact on academic performance $[24,25]$. The first, mastery goals, can be defined as the desire to develop a deep and meaningful understanding of course material with intellectual progress and/or outcome-related success being evaluated using an internal frame of reference. In other words, mastery-oriented students estimate whether they are successful in their academic pursuits based on behavioral or intellectual criteria that they have set for themselves without reference to the achievement level of classmates or expectations of parents or teachers. The second and third categories (performance 
approach and performance avoidance goals, resp.) have been found to be strongly related to an ability-focused orientation and, when evaluating performance, an external frame of reference [12]. For example, those who adopt performance approach goals are more likely to focus on outperforming others via higher grades, attaining a higher order of rank, or simply completing tasks first. It should be noted that full comprehension or mastery of course material, while perhaps a byproduct, is not a focus of a student with a strong performance approach orientation. Finally, those who adopt performance avoidance goals are more likely to engage in active attempts to avoid being exposed as incapable or less capable of completing a task when compared to their classmates.

The adoption of mastery goals has been found to be a strong predictor of students utilizing adaptive learning strategies, adopting a positive attitude toward learning and the willingness to select challenging tasks [12]. Research has also consistently linked the adoption of mastery goals to positive academic behaviors such as effort and persistence, willingness to seek help, and the use of meaningful cognitive processing strategies [26-28]. Conversely, performance avoidance and performance approach goals have been linked to maladaptive behaviors such as procrastination and the use of self-handicapping strategies $[29,30]$.

The question remains, however, as to the manner and extent to which academic achievement goals relate to (and perhaps may be predicted by) nonacademically focused constructs such as happiness. As cognitive-motivational research has consistently demonstrated a link between goals and outcomes, we argue that understanding the factors that support or inhibit the adoption of the various forms of achievement goals is a relevant and meaningful endeavor. We would also submit that a continuing convergence between the educational and positive psychology lines of research (see [22], e.g.) has the opportunity to offer researchers a more comprehensive explanation of social and academic performance.

\section{Social Goals}

The second domain of life, consistent with Lyubomirsky et al. [14], to be examined in the current study is the nature of our social relationships, specifically, the reasons we have for forming and maintaining relationships with others and how those reasons may be related to and predicted by one's happiness orientation. Traditionally, the underlying reasons for fostering and maintaining social relationships have been examined under the rubric of social goals. However, over the last fifteen years a growing number of cognitive-motivational researchers have argued that social goal research has become a tangled web of terms and concepts and, as a result, there exists a "critical need to untangle the many constructs represented by the term" [31, page 232]. In light of this call, Ryan and Shim [32] have advanced a broad three-factor social achievement goal structure mirroring the currently accepted three factor academic achievement goal framework. As such, students who possess social development goals focus on developing friendships which emphasize respect, interest, and mutual fulfillment, while students adopting social demonstration approach goals seek to demonstrate behaviors that will enhance their level and/or likelihood of acceptance by peers or result in them being evaluated as "cool" by their classmates. Finally, social demonstration avoidance goals indicate a student's desire to avoid behaviors that could result in social rejection or interpersonal appraisals of social incompetence (i.e., to be seen as notcool by their classmates). Fairchild et al. [13] found that subjective well-being scores were positively related to a social development orientation while being negatively related to social demonstration goal scores. More recently, Ryan and Shim [33] found social development goals to be positively related to perceived popularity, while social demonstration goals were found to be "positively associated with aggressive behavior and negatively associated with prosocial behavior" (p. 684).

\section{Research Questions}

As evidence builds that social and academic achievement goals are key factors in the decision making process of adolescent's, we would contend that studies which seek to identify additional related factors for both types of goals would be in the best position to offer meaningful routes to change if academically or socially oriented outcomes are found to be maladaptive. In light of Lyubomirsky et al's [14], contention that happiness is a crucial indicator of outcomes in important life domains, the goal of the current study was to, in part, test the implicit assertion that happiness is somehow related to the adoption of academically and socially relevant goals. As such, the research question guiding the current study was as follows: What are the relationships among social and academic achievement goals and routes to happiness?

\section{Methods}

6.1. Participants. The participant sample was compromised of 132 college students who were enrolled at a small, public liberal arts university in the Midwestern United States. A majority of these students were enrolled in psychology classes and received extracredit as an incentive to participate in the study. There were 44 males and 88 females with ages ranging from 18 to 58 . The average age of the participants was 22 years old (standard deviation $=6.37$ ) with approximately $80 \%$ of the respondents being between 18 to 23 years of age. Of the participants there were 36 freshman, 24 sophomore, 33 juniors, and 39 seniors. The sample consisted of $81.8 \%$ Caucasian, 6.1\% African-American, 6.1\% Native American, 3\% Hispanic/Latino, 1.5\% Asian, and 1.5\% "Other."

6.2. Materials. Participants completed a research packet containing an informed consent, three questionnaires, and a demographics sheet. The demographic sheet was used to collect basic information including participant age, grade, gender, and race/ethnicity. Each questionnaire item required a response on a 6-point Likert-style agreement scale ranging from Strongly Disagree (1) to Strongly Agree (6) with 
TABLE 1: Example items for each subscale.

\begin{tabular}{|c|c|}
\hline Mastery goal item & "It's important to me that I learn a lot of new concepts this year" \\
\hline Performance approach goal item & "It's important to me that other students at my school think I am good at my school work" \\
\hline Performance avoidance goal item & "One of my goals is to keep others from thinking I'm not smart" \\
\hline Social mastery goal item & "My goal is to have friends who really understand me" \\
\hline Social demonstration approach goal item & "My goal in most social situations is to impress others" \\
\hline Social demonstration avoidance goal item & "My goal is to avoid looking foolish in social situations" \\
\hline Eudaimonia item & "When I engage in this activity I feel that this is what I was meant to do" \\
\hline Hedonic enjoyment item & "When I engage in this activity I feel good" \\
\hline
\end{tabular}

TABle 2: Descriptive statistics for all scales and subscales.

\begin{tabular}{lcccc}
\hline Subscale & Alpha & Mean & Min-Max & SD \\
\hline (1) Eudaimonia & .791 & 3.59 & $1.0-5.0$ & .857 \\
(2) Hedonism & .736 & 3.47 & $1.5-5.0$ & .782 \\
(3) MG & .853 & 5.02 & $2.9-6.0$ & .754 \\
(4) PAP goal & .764 & 3.78 & $1.5-6.0$ & .876 \\
(5) PAV goal & .900 & 3.44 & $1.0-6.0$ & 1.22 \\
(6) SocDG & .881 & 5.11 & $2.0-6.0$ & .789 \\
(7) SocDAP & .916 & 2.71 & $1.0-5.3$ & 1.13 \\
(8) SocDAV & .922 & 3.31 & $1.0-6.0$ & 1.21 \\
\hline
\end{tabular}

Note: $n=132$.

Note: $\mathrm{MG}=$ mastery goals; PAP Goal = performance approach goal; PAV goal $=$ performance avoidance goal; SocDG $=$ social development goals; Soc $\mathrm{DAP}=$ social demonstration approach goal; SocDAV = social demonstration avoidance goal.

higher mean scores indicating a greater level of endorsement of a particular variable. For example, a mean score of 6 would indicate that a given participant strongly endorses a particular type of goal as being a reflection of their underlying goal orientation, whereas a mean score of 1 would indicate that a particular goal type does not represent a significant facet of their underlying motivation.

Academic achievement goals were measured using the Patterns of Adaptive Learning Survey (PALS; [34]). The PALS provides a three-factor 17 -item goal orientation measure that includes subscales for mastery goals (6 items), performanceapproach goals ( 5 items), and performance avoidance goals (6 items). Social goals were measured using the three factor 22-item Revised Social Goal Orientation Survey (R-SAGOS; [13]) that includes subscales for social development goals (8items), social demonstration approach goals (7 items), and social demonstration avoidance goals (7 items). Finally, the 12-item Personally Expressive Activities Questionnaire (PEAQ; $[15,35])$ was used to assess the participants' happiness orientation. The PEAQ contains a 6-item eudaimonia subscale and a 6-item hedonic subscale. Example items used to measure each construct can be seen in Table 1 .

\section{Results}

The following analyses are based on the 132 cases for which complete data was collected and analyzed. The Cronbach alpha reliability coefficients, means, and standard deviations are presented in Table 2. As evidenced in the table, reliabilities were reasonably strong for each of the scales and subscales allowing for further analysis of the data.

For descriptive purposes, correlations were examined among all variables included in the current study (see Table 3). This analysis revealed that there were positive relationships among eudaimonia and social development and academic mastery goals but no relationship between eudaimonia and either academic performance goals or either social demonstration goals. Additionally, hedonic enjoyment was found to be positively related to academic performance approach goals, social demonstration approach goals and social development goals with this last relationship perhaps indicating that meaningful social relationships (represented via social development goals) could potentially aide in the fulfillment of the immediate (hedonic) and longterm (eudaimonic) pursuit of happiness. Collectively, these results indicate that finding happiness in personal fulfillment (eudaimonia) is positively related to the desire to obtain meaning in both social and intellectual pursuits, while happiness being found in the simple pursuit of outcomes (hedonic enjoyment) is related to the desire to been seen as either the most popular or the most intellectually gifted (a social and academic approach orientation).

To address the main research question, two stepwise regression analyses were conducted using a backward elimination approach to examine the interrelations among the six goal-oriented variables (three academic achievement goals and three social achievement goals) and both eudaimonia and hedonic enjoyment. In the first regression analysis (see Table 4) involving the six goal-oriented variables predicting hedonic enjoyment, the results revealed that the final model was statistically significant $\left(R^{2}=8.8 \%, F(2,127)=4.076\right.$, $P=.008)$ with performance approach goals $(\beta=.274$, $P<.05)$ and social demonstration approach goals $(\beta=.217$, $P<.05)$ yielding significant betas. In the second regression analysis (see Table 5) involving the six goal-oriented variables predicting eudaimonia, the results revealed that the final model was statistically significant $\left(R^{2}=19.5 \%, F(2,128)=\right.$ 15.52, $P<.0001)$ with both academic mastery goals $(\beta=$ $.192, P<.05)$ and social-development goals $(\beta=.311$, $P<.001)$ yielding significant beta values.

As with the correlational findings, the regression analyses provided additional support to the contention that shortterm (hedonic) enjoyment is related to positive appraisals 
TABLE 3: Bivariate correlations among all happiness variables, academic achievement goals and social goals.

\begin{tabular}{|c|c|c|c|c|c|c|c|c|}
\hline & 1 & 2 & 3 & 4 & 5 & 6 & 7 & 8 \\
\hline (1) Eudaimonia & 1 & & & & & & & \\
\hline (2) Hedonism & -.014 & 1 & & & & & & \\
\hline (3) $\mathrm{MG}$ & $.354^{* *}$ & .144 & 1 & & & & & \\
\hline (4) PAP goal & .018 & $.218^{*}$ & $.305^{* *}$ & 1 & & & & \\
\hline (5) PAV goal & -.065 & .084 & .097 & $.773^{* *}$ & 1 & & & \\
\hline (6) SocDG & $.409^{* *}$ & $.184^{*}$ & $.517^{* *}$ & .065 & -.056 & 1 & & \\
\hline (7) SocDAP & -.046 & $.230 * *$ & .040 & $.650^{* *}$ & $.604^{* *}$ & .117 & 1 & \\
\hline (8) SocDAV & -.050 & .158 & .085 & $.585^{* *}$ & $.727^{* *}$ & .128 & $.644^{* *}$ & 1 \\
\hline
\end{tabular}

${ }^{*} P<.05 .{ }^{* *} P<.01$.

Note: MG: mastery goals; PAP goal: performance approach goal; PAV goal: performance avoidance goal; SocDG: social development goals; SocDAP: social demonstration approach goal; SocDAV: social demonstration avoidance goal.

TABLE 4: Summary of stepwise regression analysis using backward elimination approach for academic achievement goals, social goals, and hedonic enjoyment.

\begin{tabular}{|c|c|c|c|}
\hline Initial model & $\beta$ & Final model & $\beta$ \\
\hline \multirow[t]{2}{*}{ MG } & .179 & & \\
\hline & & PAP Goal & $.274^{*}$ \\
\hline \multirow[t]{2}{*}{ PAP Goal } & $.241^{*}$ & & \\
\hline & & SocDAP & $.217^{*}$ \\
\hline PAV Goal & -.191 & & \\
\hline SocDG & .098 & & \\
\hline SocDAP & $.203^{*}$ & & \\
\hline SocDAV & .099 & & \\
\hline \multicolumn{4}{|c|}{$\begin{array}{l}\text { Final } R^{2}=8.8 \% ; \Delta R^{2}=-2.1 \% \text {; final Adj } R^{2}=.066 ; F(2,127)=4.08, P< \\
.01^{*} P<.05 ; * * P<.01 \text {. } \\
\text { Note: MG: mastery goals; PAP Goal: performance approach goal; PAV goal: } \\
\text { performance avoidance goal; SocDG: social development goals; SocDAP: } \\
\text { social demonstration approach goal; SocDAV: social demonstration avoid- } \\
\text { ance goal. }\end{array}$} \\
\hline
\end{tabular}

TABLE 5: Summary of stepwise regression analysis using backward elimination approach for academic achievement goals, social goals, and eudaimonia.

\begin{tabular}{lccc}
\hline Initial model & $\beta$ & Final model & $\beta$ \\
\hline MG & .180 & & $.192^{*}$ \\
PAP Goal & .009 & SG & $.311^{* *}$ \\
PAV Goal & .052 & & \\
SocDG & $.341^{* *}$ & & \\
SocDAP & -.057 & & \\
SocDAV & -.114 & & \\
\hline
\end{tabular}

Final $R^{2}=19.5 \% ; \Delta R^{2}=-1.3 \%$; final Adj $R^{2}=.183 ; F(2,128)=15.52, P<$ $.0001 * P<.05 ; * * P<.01$.

Note: MG: mastery goals; PAP goal: performance-approach goal; PAV goal: performance avoidance goal; SocDG: social development goals; SocDAP; social demonstration approach goal; SocDAV: social demonstration avoidance goal.

from others, while those holding a eudaimonic orientation seek a sense of mastery or personal fulfillment in both academic and social realms. While experiencing happiness as a result of praise is to be expected, the aforementioned results are significant in that when one depends upon recognition from others to provide the sole route to happiness, it is conceivable that enduring happiness will prove elusive as an individual must continually focus on the expectations and desires of others in the attempt to maintain those positive appraisals. As a result, attempts at establishing meaningful and mutually beneficial relationships may be excluded or severally restricted.

The results of the regression analyses also indicated that eudaimonia and not hedonic enjoyment was predictive of social development goals. Collectively, the results of the correlational analyses indicated that although there is a relationship between meaningful relationships and hedonic enjoyment only eudaimonia is useful in the prediction of social development goals and therefore is the route to happiness most likely to result in the formation and maintenance of consequential relationships. Finally, neither social demonstration avoidance nor academic performance avoidance goals were meaningfully related to either route to happiness as evidenced by the results from both the correlational and regression analyses.

\section{Discussion}

In a recent examination of the links between intrinsic motivation (as defined within Self-Determination Theory) and routes to happiness, Ryan et al. [22] argued that "defining health and wellness is not only of theoretical interest... but also has substantial applied significance," predominantly within the realm of developing and utilizing effective educational interventions (p. 141). As such, it is perhaps most appropriate to examine the pursuit of happiness using a sample of college students. For traditional aged students, leaving home and attending college is their first opportunity to meaningfully pursue interests free from immediate parental or adult supervision. As a result, most college students will have the freedom and ability to accept and pursue challenges they consider personally fulfilling and reject pursuits that lead to frustration and unhappiness. Ultimately, we would argue that the current study benefits from a sample that is predominately populated by those at a point in life where they can most freely pursue what makes them happy (i.e., 
relationships, a specific area of study, etc.). Therefore, it is important to note again that different routes to happiness were related to different set of relational and academic goals. Consequently, those who work with students, college students in this case, could likely benefit from investigating the underlying route to happiness that a student is pursuing if relational and/or academic dissatisfaction is noted.

Further, by examining the relationship among and between routes to happiness and goals, we have sought to shed light on an additional set of factors that could be used to explain the selection of one's goal orientation in multiple domains. This is potentially powerful set of connections to examine and understand since one's desire to be happy would likely be an enduring characteristic, and results of that pursuit would be felt across the multiple facets of life beyond academics and social relationships.

\section{Limitations}

As with any study based on correlational evidence, care must be taken in the interpretation and generalization of the findings. Specifically, the nature of the evidence does not support a causal link between examined variables even if one, in truth, does exist. Additional research would therefore be warranted to further investigate additional relational dimensions between and among the variables explored in the present study.

Furthermore, a larger sample with a more even distribution of gender and race could also stand to strengthen the findings as would sample participants from beyond the Midwestern United States and from larger universities. Finally, while the purpose of this study was to fill a very specific gap in the cognitive-motivational literature pertaining specifically to the relations between goals and happiness, future studies would benefit from taking into account a wider range of predictor and/or outcome-related variables including but not limited to retention, grades, cognitive engagement, and so on.

\section{Conclusion}

Based on the findings of the current study, future research is warranted to further explore and articulate ways in which the pursuit of happiness can serve as a meaningful lens through which to understand the academic and social pursuits of students. As Aristotle postulated many centuries ago, one's primary ambition is to be happy. However, based on the current formulation of happiness as a psychological construct it's not simply enough to think about a student's level of happiness but to take a further step in understanding what type of happiness one wishes to achieve. This is important as the type of happiness one chooses to pursue is related to the means by which one chooses to pursue it. Specifically, the evidence suggests that if one seeks hedonic enjoyment one is likely to focus on elements of quantity (more friends, more success, and higher grades) with a potential consequence being that too stringent, a focus on quantity might lead to a loss of quality. Conversely, someone pursuing eudaimonia will more likely focus on developing quality relationships and, in the context of academics, a higher level of mastery over course material making, it might be assumed a greater contribution to long-term well-being. Ultimately, the findings of the current study support the contention that by including a route to happiness variable into one's analysis as a key predictor, educational researchers, classroom teachers, and school administrators will have a more thorough explanation as to the source of the social and academic achievement goals students choose to adopt.

\section{References}

[1] M. Csikszentmihalyi, Flow: The Psychology of Optimal Experience, Harper Perennial, New York, NY, USA, 1990.

[2] V. E. Frankl, Man's Search For Meaning, Washington Square Press, New York, NY, USA, 1985.

[3] V. E. Frankl, Man's Search for Meaning, Washington Square Press, New York, NY, USA, 1946.

[4] M. E. P. Seligman, Flourish: A Visionary New Understanding of Happiness and Well-Being, Free Press, New York, NY, USA, 2011.

[5] C. R. Snyder, Handbook of Hope: Theory, Measures, and Applications, Academic Press, San Diego, Calif, USA, 2000.

[6] M. E. P. Seligman, Authentic Happiness: Using the New Positive Psychology to Realize Your Potential for Lasting Fulfillment, Free Press, New York, NY, USA, 2003.

[7] M. E. P. Seligman, Learned Optimism: How to Change Your Mind and Your Life, Vintage Press, New York, NY, USA, 2006.

[8] M. E. P. Seligman, R. M. Ernst, J. Gillham, K. Reivich, and M. Linkins, "Positive education: positive psychology and classroom interventions," Oxford Review of Education, vol. 35, no. 3, pp. 293-311, 2009.

[9] C. L. M. Keyes and S. J. Lopez, "Toward a science of mental health: positive directions in diagnosis and interventions," in Handbook of Positive Psychology, C. R. Snyder and S. J. Lopez, Eds., pp. 45-62, Oxford University Press, New York, NY, USA, 2002.

[10] K. J. Reivich, M. E. P. Seligman, and S. McBride, "Master resilience training in the U.S. army," American Psychologist, vol. 66, no. 1, pp. 25-34, 2011.

[11] M. Bolt, Pursuing Human Strengths, Worth Publishers, New York, NY, USA, 2004.

[12] A. J. Elliot, H. A. McGregor, and S. Gable, "Achievement goals, study strategies, and exam performance: a mediational analysis," Journal of Educational Psychology, vol. 91, no. 3, pp. 549-563, 1999.

[13] A. J. Fairchild, S. J. Horst, S. J. Finney, and K. E. Barron, "Evaluating existing and new validity evidence for the Academic Motivation Scale," Contemporary Educational Psychology, vol. 30, no. 3, pp. 331-358, 2005.

[14] S. Lyubomirsky, L. King, and E. Diener, "The benefits of frequent positive affect: does happiness lead to success?" Psychological Bulletin, vol. 131, no. 6, pp. 803-855, 2005.

[15] A. S. Waterman, "Two conceptions of happiness: contrasts of personal expressiveness (eudaimonia) and hedonic enjoyment," Journal of Personality and Social Psychology, vol. 64, no. 4, pp. 678-691, 1993.

[16] C. Ames and J. Archer, "Achievement goals in the classroom: students' learning strategies and motivation processes," Journal of Educational Psychology, vol. 80, no. 3, pp. 260-267, 1988.

[17] C. A. Wolters, "Self-regulated learning and college students' regulation of motivation," Journal of Educational Psychology, vol. 90, no. 2, pp. 224-235, 1998. 
[18] J. M. Friedel, K. S. Cortina, J. C. Turner, and C. Midgley, "Changes in efficacy beliefs in mathematics across the transition to middle school: examining the effects of perceived teacher and parent goal emphases," Journal of Educational Psychology, vol. 102, no. 1, pp. 102-114, 2010.

[19] J. Kim, D. L. Schallert, and M. Kim, "An integrative cultural view of achievement motivation: parental and classroom predictors of children's goal orientations when learning mathematics in Korea," Journal of Educational Psychology, vol. 102, no. 2, pp. 418-437, 2010.

[20] C. Darnon, B. Dompnier, O. Gilliéron, and F. Butera, "The interplay of mastery and performance goals in social comparison: a multiple-goal perspective," Journal of Educational Psychology, vol. 102, no. 1, pp. 212-222, 2010.

[21] R. Pekrun, A. J. Elliot, and M. A. Maier, "Achievement goals and achievement emotions: testing a model of their joint relations with academic performance," Journal of Educational Psychology, vol. 101, no. 1, pp. 115-135, 2009.

[22] R. M. Ryan, V. Huta, and E. L. Deci, "Living well: a selfdetermination theory perspective on eudaimonia," Journal of Happiness Studies, vol. 9, no. 1, pp. 139-170, 2008.

[23] A. Maslow, Toward a Psychology of Being, Van Nostrand, New York, NY, USA, 1962.

[24] A. Kaplan, E. Lichtinger, and M. Gorodetsky, "Achievement goal orientations and self-regulation in writing: an integrative perspective," Journal of Educational Psychology, vol. 101, no. 1, pp. 51-69, 2009.

[25] K. Murayama and A. J. Elliot, "The joint influence of personal achievement goals and classroom goal structures on achievement-relevant outcomes," Journal of Educational Psychology, vol. 101, no. 2, pp. 432-447, 2009.

[26] E. M. Anderman, T. Griesinger, and G. Westerfield, "Motivation and cheating during early adolescence," Journal of Educational Psychology, vol. 90, no. 1, pp. 84-93, 1998.

[27] A. J. Elliot and J. M. Harackiewicz, "Approach and avoidance achievement goals and intrinsic motivation: a mediational analysis," Journal of Personality and Social Psychology, vol. 70, no. 3, pp. 461-475, 1996.

[28] B. A. Greene, R. B. Miller, H. M. Crowson, B. L. Duke, and K. L. Akey, "Predicting high school students' cognitive engagement and achievement: contributions of classroom perceptions and motivation," Contemporary Educational Psychology, vol. 29, no. 4, pp. 462-482, 2004.

[29] A. J. Elliot and M. A. Church, "A hierarchical model of approach and avoidance achievement motivation," Journal of Personality and Social Psychology, vol. 72, no. 1, pp. 218-232, 1997.

[30] A. J. Elliot and K. M. Sheldon, "Avoidance achievement motivation: a personal goals analysis," Journal of Personality and Social Psychology, vol. 73, no. 1, pp. 171-185, 1997.

[31] T. C. Urdan and M. L. Maehr, "Beyond a two-goal theory of motivation and achievement: a case for social goals," Review of Educational Research, vol. 65, pp. 213-243, 1995.

[32] A. M. Ryan and S. Shim, "Social achievement goals: the nature and consequences of different orientations toward social competence," Personality and Social Psychology Bulletin, vol. 32, no. 9, pp. 1246-1263, 2006.

[33] A. M. Ryan and S. S. Shim, "An exploration of young adolescents' social achievement goals and social adjustment in middle school," Journal of Educational Psychology, vol. 100, no. 3, pp. 672-687, 2008.

[34] C. Midgley, M. L. Maehr, L. Z. Hruda, E. Anderman, L. Anderman, K. E. Freeman et al., Manual for the Patterns of
Adaptive Learning Scales (PALS), University of Michigan, Ann Arbor, Mich, USA, 2000.

[35] A. S. Waterman, S. J. Schwartz, and R. Conti, "The implications of two conceptions of happiness (hedonic enjoyment and eudaimonia) for the understanding of intrinsic motivation," Journal of Happiness Studies, vol. 9, no. 1, pp. 41-79, 2008. 


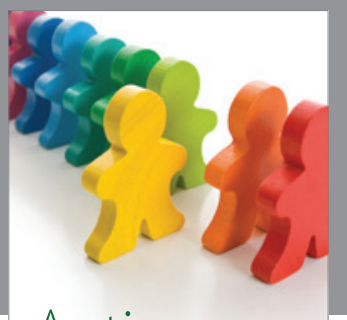

Autism

Research and Treatment
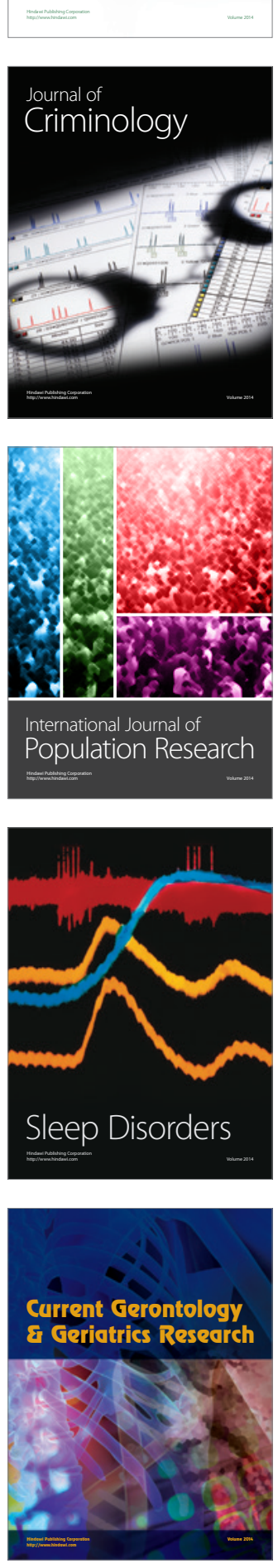
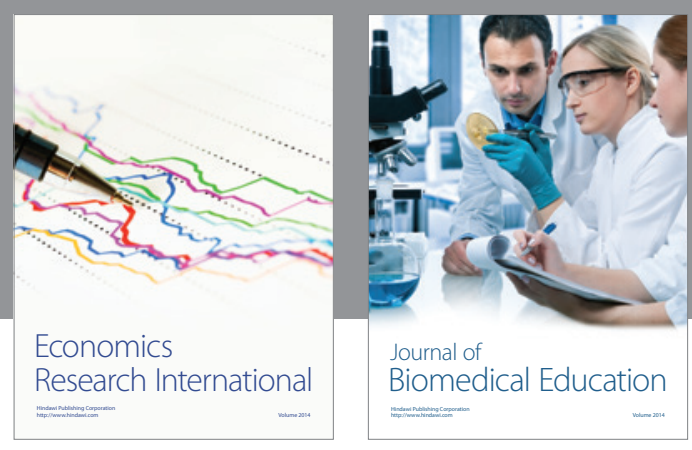

Journal of

Biomedical Education

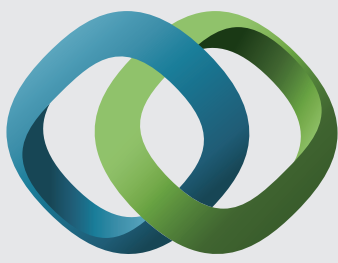

\section{Hindawi}

Submit your manuscripts at

http://www.hindawi.com
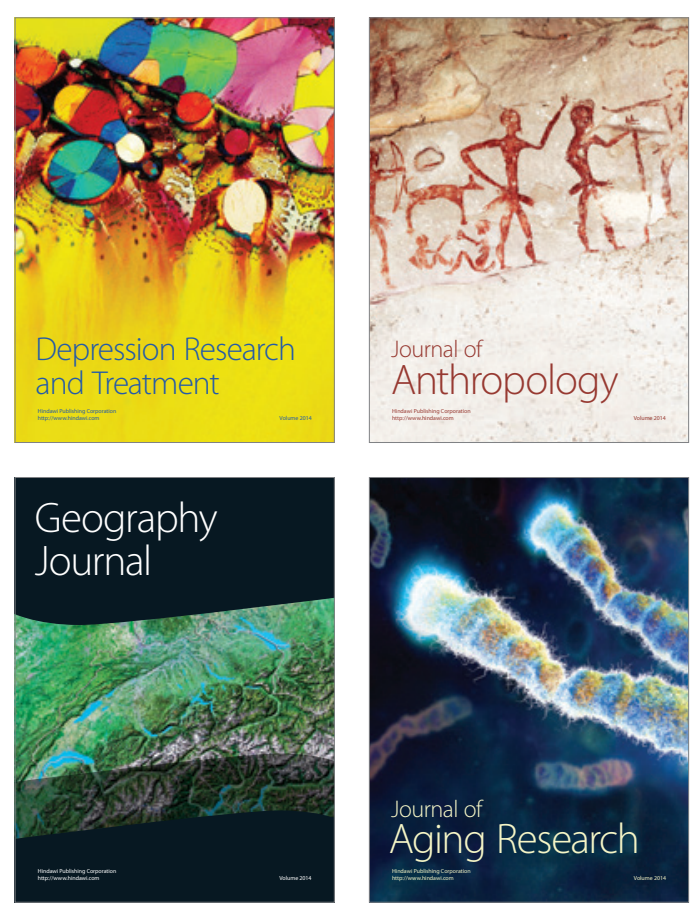

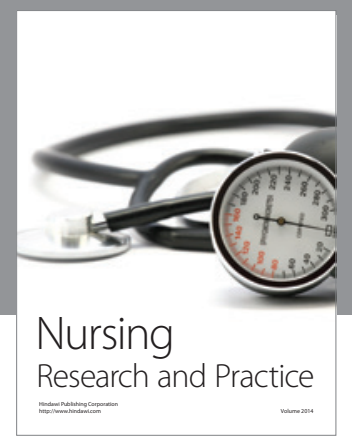

Nursing

Research and Practice

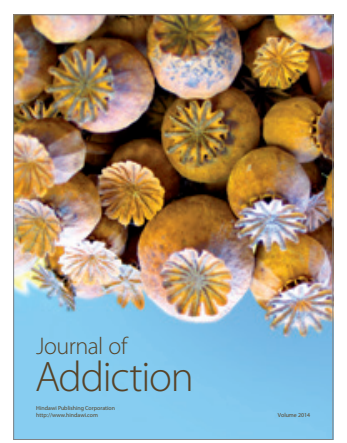

Child Development

Research

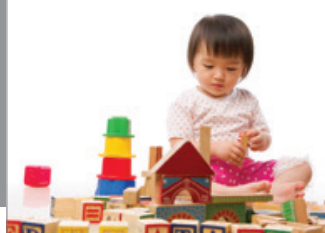

迥
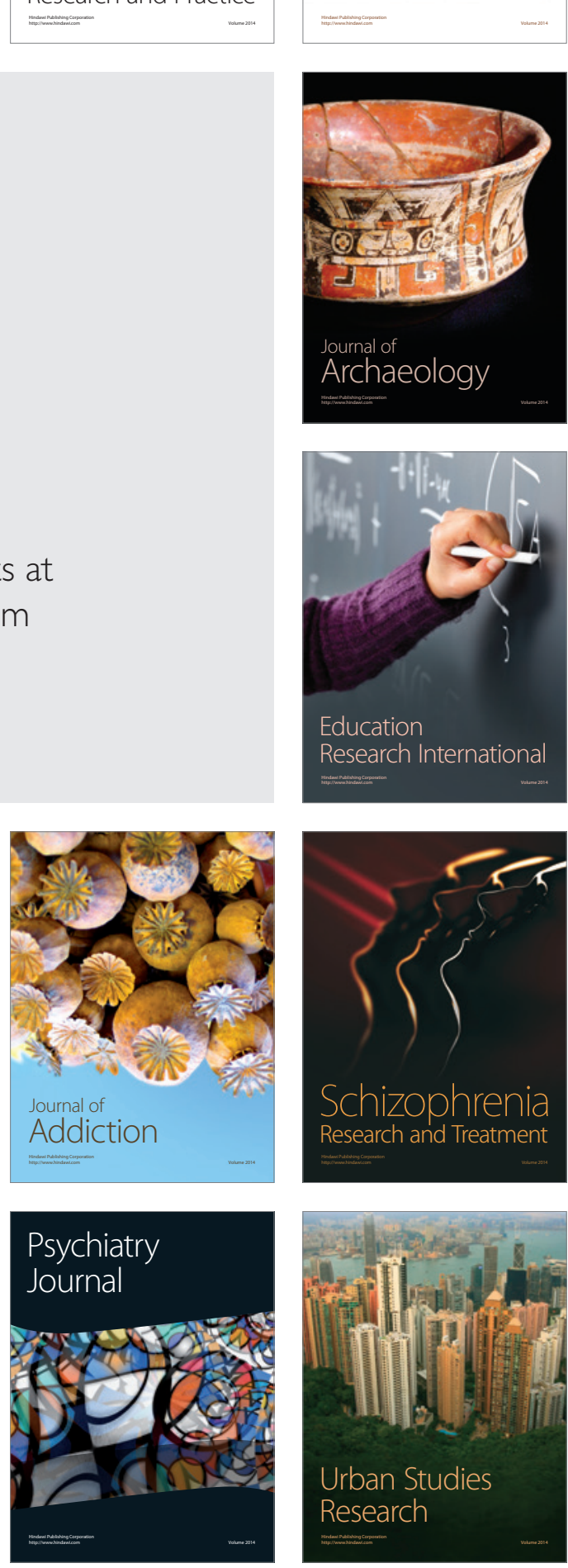